\title{
LA PRESENCIA DE ORTEGA Y GASSET EN EL PENSAMIENTO MEXICANO
}

En 1943, en el primer estudio sistemático sobre el desarrollo del pensamiento mexicano, Historia de la filosofía en México, de Samuel Ramos, se incluye una sección titulada "La influencia de Ortega y Gasset". Allí se considera el postulado orteguiano, "Yo soy yo y mi circunstancia, y si no la salvo a ella no me salvo yo", como la piedra angular sobre la que se eleva el edificio de la " $f i$ losofía de lo mexicano". Y el mismo Samuel Ramos reconoce a continuación su deuda con Ortega. Esta apreciación de Ramos, que recogen y proyectan después José Gaos y los miembros del Grupo Hiperión ${ }^{1}$, ha llegado a' ser hoy día lugar común en las evaluaciones y exposiciones del desarrollo del pensamiento mexicano.

No obstante este tácito acuerdo, tanto entre los pensadores mexicanos actuales como entre los críticos ${ }^{2}$, de atribuir a la obra de Ortega y Gasset una influencia decisiva en el desarrollo del pensamiento mexicano desde la década de los veinte hasta nuestros días, no se ha analizado en qué consiste tal influencia, ni se han

${ }^{1}$ Me refiero aquí, entre otros, a Joaquín MacGregor, Octavio Paz, Jorge Portilla, Emilio Uranga, Luis Villoro y Leopoldo Zea.

${ }^{2}$ De entre los más representativos al respecto destacan: Solomon LiPP, Leopoldo Zea. From 'Mexicanidad' to a Philosophy of History, Waterloo, 1980; PA. Trick Romanell, Making of the Mexican Mind: A study in Recent Mexican Thought, Lincoln, 1952; “Ortega in Mexico: A Tribute to Samuel Ramos”, JIII, 21 (1960), 600-608, y "Samuel Ramos on the Philosophy of Mexican Culture: Ortega and Unamuno in Mexico", LARR, 1975, núm. 3, 81-101; FERNAN Do Salmerón, Las mocedades de Ortega y Gasset, México, 1959 y "Las ideas estéticas de Ortega y Gasset", FyL, 26 (1953), núms. 51/52, 141-157; HENRY C. Schmidt, The Roots of lo Mexicano: Self and Society in Mexican Thought, 1900-1934, College Station, 1978; LEOPOLDO ZEA, "Ortega el Americano", CuA, 1956, núm. 1, 132-145. 
precisado cuáles postulados orteguianos fueron aceptados y cuáles rechazados, ni las razones que en cada momento motivaron la aceptación o el rechazo de un aspecto de su obra. Y ello nos lleva a juicios contradictorios en la valoración de su influencia. Así, por ejemplo, mientras que una breve lectura de las obras de Leopoldo Zea - el filósofo mexicano actual más sobresalientenos permitiría afirmar con Solomon Lipp que "la influencia de Ortega en el pensamiento de Zea es indiscutible", dos de una encuesta realizada por la revista mexicana Occidente en 1945, en torno al tema general de "Los libros fundamentales de nuestra época", demuestran que al desligar la obra de Ortega de un contexto determinado apenas si se le da importancia ${ }^{4}$.

Ante una situación tan peculiar, se hace evidente el riesgo que correrá todo intento de determinar la repercusión de la obra de Ortega y Gasset en México. Más aún, el alcance limitado de lo escrito sobre el tema hasta la fecha se debe, en mi opinión, a que sus autores se preocuparon más de juzgar la posición filosófica orteguiana con relación a sus propias ideas - lo que significaba partir de unos supuestos apriorísticos - que de analizar el panorama ideológico mexicano antes de la llegada de la obra de Ortega, como base indispensable para luego determinar qué ideas aceptaron, cómo se incorporaron y por qué. Además, estos estudios, que partían de Ortega y de su obra y que trataban de establecer su influencia en México, se aproximaban necesariamente desde afuera y apenas se quedaban en la periferia, con una visión forzosamente fragmentaria del lugar que lo orteguiano ocupaba en el desarrollo del pensamiento mexicano.

Con el fin de evitar estas limitaciones, he dirigido mi investi-

3 S. LiPP, op. cit., p. 131.

4 La encuesta de Occidente, bajo el título de "Los libros fundamentales de nuestra época', se publicó en los números 2 (1945), 1-16 y 3 (1945), 27-35. Las respuestas son, en verdad, muy desiguales, aunque en ella participaron 28 de los intelectuales más destacados de aquel momento mexicano (incluyendo algunos de los españoles transterrados). Los 25 autores que obtuvieron un mínimo de tres menciones quedaron reunidos, según el número de éstas, en nueve grupos. Pues bien, Ortega y Gasset, con el mínimo de tres menciones, aparece en el noveno grupo (Unamuno, el otro autor de lengua española, se encuentra en el sexto). Todavía es más significativo que la obra mencionada sea La rebelión de las masas, cuando, por razones que luego comentaremos, fue una de las obras de Ortega menos influyentes en el medio mexicano. Conviene añadir, sin embargo, que la encuesta, por lo amplio de la pregunta y por las diversas interpretaciones a que dio lugar, apenas tiene valor científico. No obstante, sí nos sirve para resaltar en el caso de Ortega una disparidad entre la influencia que se le atribuye y el reconocimiento que se le concede. 
gación al estudio del desarrollo del pensamiento mexicano en la primera mitad del siglo XX. He estudiado también a México como entidad independiente, aunque enlazando su evolución a la circunstancia occidental con la que forzosamente tiene que contar. El Ortega que así se descubre se asemeja al comienzo a una sombra de contornos concretos, que pronto se agiganta cubriéndolo todo, al mismo tiempo que su presencia se hace más difusa y difícil de precisar. Es, por decirlo así, como un escape fino de humo en un cuarto cerrado; delimitado y reconocible al principio, pero que pronto lo cubre todo y nada en concreto, y que además deja la abertura por la que penetró libre a la entrada de nuevas corrientes.

\section{MÉXICO EN LA DÉCADA DE LA REvंOLUCIÓN}

A comienzos de siglo, la fe en el positivismo, que había dominado en el último tercio del siglo xIX en México, está en franca decadencia. El porfiriato comienza a resquebrajarse por dos frentes: el político y el ideológico. Los intelectuales mexicanos, al menos los más destacados, coinciden en que el positivismo no ha producido los resultados que prometía. Pero todavía entonces se culpaba del fracaso a la ideología misma y a sus posibles errores. El hecho de que ésta hubiera sido importada, de que no respondiera a la circunstancia mexicana, tanto por serle extraña como por no considerar sus problemas, pasaba desapercibido a los intelectuales, quienes de nuevo buscaban fuera las soluciones a sus problemas. Antonio Caso diría años después: "Antes de la revolución, durante el gobierno del general Díaz, [...] en la cátedra, en el púlpito, en el senado, en la clínica, en el foro, la voz unánime, vox populi, reconocía la subordinación de nuestro movimiento cultural al movimiento cultural europeo. Éramos, oficialmente, una sociedad de copistas, un trasunto imperfecto de lo que acaecía allende el Atlántico" 5 . La reacción contra el positivismo, sin embargo, traía también consigo el primer paso hacia una independencia cultural. Se podían importar las últimas manifestaciones filosóficas europeas, pero se requería su adaptación a los problemas nacionales. Tal es la posición de Justo Sierra en el discurso que pronunció en 1910 con motivo de la inauguración de la Universidad Nacional. Sierra abogaba por una universidad que

${ }^{5}$ Antonio Câso, "La espada de dos filos", en Obras compleias, México, 1976, t. 9, p. 321. 
"se propusiera adquirir los medios de nacionalizar la ciencia, de mexicanizar el saber"' 6 .

El cambio no podía tardar. En el frente político Francisco Madero se levantó contra Porfirio Díaz y comenzó la Revolución el 20 de noviembre de 1910. En octubre de 1911, Madero es nombrado presidente. En el campo intelectual, se funda a finales de 1909 el Ateneo de la Juventud ${ }^{7}$, cuyos miembros mantienen una posición de decidido antipositivismo, en un ambiente de libertad y de énfasis en los estudios filosófico-literarios de los clásicos de la civilización occidental. Ambos intentos, sin embargo, resultaban de nuevo artificiales y, ante todo, ajenos a la realidad nacional. En lo político, Madero inaugura un gobierno acomodaticio, de lenta evolución, que no satisface a nadie: los campesinos del sur se levantan en armas acaudillados por Emiliano Zapata, mientras que las derechas traicionan y asesinan a Madero. Por su parte, los miembros del Ateneo, nos dice Gómez Morín, "no tuvieron tiempo, tampoco, de definir conclusiones. Quizá hasta estaban — con excepción de Vasconcelos - alejados de la vida mexicana. Demasiado intelectualizados, demasiado europeizados [... E] El grupo se deshizo pronto"'8.

En 1913, a partir de la muerte de Madero, la Revolución entra en su etapa más virulenta. El caos reina por doquier; la máquina del gobierno se paraliza y México queda aislado en su lucha interna. El aislamiento se intensifica con la guerra europea. Y por primera vez en su historia, México se encuentra solo, solo ante sus problemas y solo en la búsqueda de soluciones. Gómez Morín nos describe así el proceso: "El aislamiento forzado en que estaba la República por el curso de la lucha militar, favoreció la manifestación de un sentido de autonomía. Poco podíamos recibir del extranjero. Razones militares y aun monetarias nos impedían el conocimiento diario y verídico de los sucesos exteriores y la importación de los habituales artículos europeos o yanquis de consumo material o intelectual. Tuvimos que buscar en nosotros mismos un medio de satisfacer nuestras necesidades de cuerpo y alma. Empezaron a inventarse elementales sustitutos de los antiguos productos importados. Y con optimista estupor nos di-

${ }^{6}$ JUSto Sierra, "Discurso en la inauguración de la Universidad Nacional", en J. L. Martínez (ed.), El ensayo mexicano moderno, México, 1958, t. 1, p. 60 .

${ }^{7}$ Entre los miembros originales del Ateneo destacan: Jesús T. Acevedo, Antonio Caso, Enrique González Martínez, Martín Luis Guzmán, Pedro Henríquez Ureña, Alfonso Reyes y José Vasconcelos.

${ }^{8}$ Manuel Gómez Morín, 1915, México, 1927, pp. 5-6. 
mos cuenta de insospechadas verdades. Existía México. México como país con capacidades, con aspiración, con vida, con problemas propios".

En este ambiente de autodescubrimiento publicó Martín Luis Guzmán, en 1915, La querella de México, que constituye un valioso documento del palpitar de la época. Con él se inicia un nuevo sentir que luego sería la base común que daría cuerpo a la llamada generación de 1915. Todo el libro tiene la fuerza de un manifiesto en pro de unos fines concretos, por lo que desde el principio señala su autor: "Por fuera de propósito que llegue a parecer lo que en estas páginas se dice, algo hay en ellas que quedará en pie, aun el peor de los casos: la afirmación del deber imperioso, insoslayable ya, de hacer una revisión sincera de los valores sociales mexicanos, revisión orientada a iluminar el camino que está por seguirse" $" 10$. En el desarrollo de su ensayo Martín Luis Guzmán sigue una estructura simple y eficaz. Por una parte señala la notoria ignorancia ante lo nacional, que ha permanecido desdeñado y oculto: "Casi nada sabemos de la historia de México - porque, como no está escrita, para medio entenderla hay que fatigarse entre muchos papeles-; pero algún manual hemos leído de la historia de Francia, de la historia de Inglaterra o de la historia de los Estados Unidos, y eso nos basta. No sabemos de motín que no sea explicable por el mecanismo de la Revolución Francesa, ni entendemos de Constitución que no parezca a la Constitución yanqui" "11. Al mismo tiempo que resalta la falta de conocimiento de lo propio, da énfasis al hecho de que México, por su situación y por su gente, es diferente a los demás países en su modo de ser y en sus necesidades: "Propendemos los mexicanos, por razones educativas, a ver siempre las cuestiones que atañen a nuestro país - tan peculiar en su origen, en sus elementos formativos y en su historia - paralelamente a las que ha suscitado la vida de otros pueblos a los cuales nos parecemos muy poco" 12 . Una vez establecidas estas dos premisas, o esa, que por desprecio e ignorancia se desconoce a México y que por sus características México es diferente, Martín Luis Guzmán reclama no sólo la necesidad de descubrir a México, sino también que este conocimiento se haga a través de lo mexicano mismo, único modo, según él, de conse-

${ }^{9}$ Ibid., pp. 7-8.

10 Martín Luis Guzmán, La querella de México, en Obras completas, México, 1961, t. 1, p. 8.

11 lbid., p. 10.

12 Ibid., p. 9. 
guir la independencia cultural y, en definitiva, una verdadera inteligencia de lo mexicano. Por ello dirá: "Por baja que nos parezca su calidad, el material patrio es el que debemos trabajar, poniendo en él nuestras manos y aplicándole las reglas que le cuadren", 13. En este proceso de interiorización y reflexión participaron no sólo los intelectuales, sino que, a través de éstos, los mismos revolucionarios fueron adquiriendo conciencia del significado de su lucha ${ }^{14}$. La Revolución fue definiéndose en sus propósitos: el problema agrario llega a ser tema central y a él se une formalmente el problema obrero; pero además de la lucha, como indica Gómez Morín, "nació el propósito de reivindicar todo lo que pudiera pertenecernos: el petróleo y la canción, la nacionalidad y las ruinas"'15.

\section{TOMA DE CONCIENCIA Y RECUPERACIÓN DE LA CIRCUNSTANCIA MEXICANA}

Con el Congreso de Querétaro y la adopción de la Constitución de 1917, la Revolución entra en su última etapa. El poder militar empieza a consolidarse y al mismo tiempo van desapareciendo los caudillos revolucionarios ${ }^{16}$; para el comienzo de la nueva década, la revolución armada puede considerarse conclui-

13 Ibid., p. 11.

14 Buen ejemplo de este proceso es la novela de Mariano Azuela, Los de abajo, publicada precisamente en 1915. Azuela mismo había participado en la lucha armada, al igual que el intelectual Luis Cervantes de su novela. Hay dos momentos en esta obra que corroboran, mejor que ningún otro documento, el cambio al que aquí nos venimos refiriendo. En el primero, al principio de la obra, Azuela señala la falta de una ideología clara en los revolucionarios en el diálogo entre el estudiante de medicina y periodista Luis Cervantes y Demetrio Macías, jefe del grupo de revolucionarios: "Yo persigo los mismos ideales y defiendo la misma causa que ustedes defienden. Demetrio sonrió: - ¿Pos cuál causa defendemos nosotros? ... Luis Cervantes, desconcertado, no encontró qué contestar", Los de abajo, México, 1970, p. 21.

El segundo momento coincide con la etapa clave en la que se va a dar batalla a Huerta, y en él Luis Cervantes trata de convencer a Demetrio Macías de que su lucha no es contra un cacique, sino por un ideal: "Mentira que usted ande por aquí por don Mónico, el cacique; usted se ha levantado contra el caciquismo que asola toda la nación. Somos elementos de un gran movimiento social que tiene que concluir por el engrandecimiento de nuestra patria ... Eso es lo que se llama luchar por principios, tener ideales' (pp. 44-45).

15 M. Gómez Morín, op. cit., p. 10.

16 Emiliano Zapata es asesinado en 1919. En 1920 muere Venustiano Carranza en una emboscada. Francisco Villa, muerto Carranza, depone las armas y se retira a un rancho en Durango, donde vive hasta su asesinato en 1923. 
da. En 1920, Álvaro Obregón es nombrado presidente de la República y con su gobierno se inicia el lento proceso de poner en práctica la Constitución. Había llegado el momento de la reflexión en un intento consciente de comprender el significado de la Revolución.

La liberación social venía acompañada de un descubrimiento de lo mexicano y de una repulsa de todo aquello que no respondiera a la propia circunstancia. Del nacionalismo político se había pasado a un decidido nacionalismo cultural. México surgía al mundo moderno con una fuerte identidad que se manifestaba con singular vigor en las artes. El esfuerzo era individual y carecía todavía de una base filosófica común, pero precisamente por ello era más significativo; pues surgía casi con fuerza espontánea de lo más íntimo del funcionar de una nueva sociedad. La comprensión de este sentir y su manifestación en las artes es la base imprescindible para la inteligencia del México post-revolucionario. Y aunque peque de esquemático por las limitaciones que este estudio me impone, voy a examinar brevemente algunas de estas manifestaciones.

Una de las consecuencias que trajeron consigo casi desde el principio, la lucha y el desorden revolucionarios, fue un cambio brusco en el ambiente musical. Las novedades europeas no llegaban y los músicos y directores de orquesta extranjeros se negaban a actuar. Mientras tanto, en las salas de fiesta, ocupadas ahora por las muchedumbres revolucionarias, triunfaba la música popular, que despertaba en el auditorio emociones antes nunca sentidas. Ya para 1915 el compositor Manuel Ponce empieza a dar cierto tono académico a su obra inspirada en lo mexicano ${ }^{17}$. Este resurgir de la música autóctona recibe ahora, además, el refuerzo de un modelo que alcanzó éxito. Carlos Chávez manifiesta este sentir en su ensayo "Importancia actual del florecimiento de la Música Nacional”, de 1916: “Los rusos nos han enseñado a realizar obra folk-lorista, y nos han mostrado la importancia que esto tiene, y ya que nosotros en nuestro pueblo poseemos como ellos los elementos necesarios para la realización de una obra semejante en su índole, y que así tendremos una escuela propia,

17 En 1916 dirá José VASCONCELos a este propósito: "La música que Manuel Ponce compone tiende a formar una escuela mexicana. Con temas arrancados del canto popular de las distintas zonas del país, hace danzas, rapsodias y aun sinfonías; su obra intensa, acertadísima, constituye una de las expresiones más genuinas del carácter mexicano", "El movimiento intelectual contemporáneo de México'”[1916], en Obras completas, México, 1957, t. 1, p. 76. 
una Escuela Mexicana que se distinga por sí misma de todas las demás, realicémosla [...] y podamos decir algún día hablando de música: La Escuela Mexicana"'18. El triunfo fue rápido, y ya en 1919 puede hablarnos Rubén Campos de la "música mexicana" y de su triunfo a partir de los conciertos del bosque de Chapultepec ${ }^{19}$. Con el éxito y el apoyo del pueblo se llega pronto a pensar que sólo es digna del mexicano aquella música que arranca de una circunstancia también mexicana; de ahí que, yendo ahora al otro extremo, se pase a satirizar y combatir todo lo que parezca tener origen europeo: "Hay aún muchos — nos dice Adolfo Salazar en 1921 - que con la cara negra y los rasgos aztecas se ponen cuello planchado y fabrican música europea. ¡Qué error profundo! ¡Como si no fuera mucho más interesante ser negro o ser azteca!"'20 De un mimetismo absoluto durante el porfiriato se pasa ahora a un deseo también absoluto de originalidad. Tal fiebre indigenista representaba, sin embargo, la euforia de un triunfo todavía reciente y la necesidad de combatir la herencia de siglos de colonialismo cultural. Para finales de los años veinte se hace patente lo fecundo de la nueva actitud, que se presenta como el camino a seguir para poder elevar lo nacional al rango de lo universal. Samuel Ramos, hablando de Strawinsky, dirá que " "nadie como él ha operado con los elementos nacionales de su arte una renovación tan decisiva en la música. Es desde luego de los pocos músicos contemporáneos, como Manuel de Falla, Béla Bartók, cuya trascendencia europea se debe nada menos que a una sabia utilización de la tradición nacional"'21. Pero Ramos señala también que la imitación, tanto la de elementos nacionales como la de extraños, no conduce a lo original y que la grandeza no radica en imitar lo autóctono, sino en el proceso de crear con los elementos que uno siente como propios, pues "en verdad Strawinsky ha usado muy poco de los temas folk-lóricos ya hechos.

${ }^{18}$ Carlos Chávez Ramírez, "Importancia actual del florecimiento de la Música Nacional', Gladios, 1 (1916), p. 34.

${ }^{19}$ Señala Rúbén M. Campos: "A Miguel Lerdo de Tejada corresponde el honor de haber hecho la apoteosis de la música popular mexicana con su Orquesta Típica en las audiciones del bosque de Chapultepec, con un numeroso personal en el que estaban representados todos los instrumentos musicales mexicanos, y con cantantes que entonaban nuestras canciones. A partir de entonces, la música mexicana quedaba consagrada" ("Las fuentes del folklore mexicano", Revista Musical de México, 1, 1919, 22-23). 354.

${ }^{20}$ AdOLFo SALAZAR, “Indigenismo y europeización', El Maestro, 1 (1921),

${ }^{21}$ Samule Ramos, "El caso Strawinsky", Contemporáneos, 5 (1929), 127-128. 
Para ser nacional, un artista no necesita tomar de fuera sus temas, cuando su genio está acorde con el estilo de su raza. Entonces encontrará en su interior, con el solo instinto, las mismas formas que ha creado el arte colectivo"'22.

Este deseo de descubrir y experimentar lo nacional no se limita a una minoría, sino que surge del pueblo mismo; y en sus principios se opone incluso a la minoría culta anclada todavía en la imitación de los gustos europeos dominantes durante el porfiriato. Precisamente a sus orígenes populares debe el hecho de que el cambio fuera total, es decir, que no se limitara a aspectos aislados de las manifestaciones culturales de México. El mismo proceso descrito en el caso de la música se repite en la arquitectura. En efecto, si hasta la Revolución se imitaba en la construcción de la casa mexicana los modelos suizos y franceses, comienza, hacia 1913, el uso de elementos coloniales adaptados a técnicas modernas. Así, por ejemplo, vuelve a ser popular el uso de patios y balcones tan a tono con el clima y el ser mexicanos, mientras que se elimina el "hall" cerrado de influencia extranjera. El retorno a lo mexicano fue tan espontáneo y decidido que ya en 1925 puede Henríquez Ureña decir que "los barrios nuevos de la capital, entregados antes al culto del hotel afrancesado y del chalet suizo, están llenos de edificios en que la antigua arquitectura del país reaparece adaptándose a fines nuevos" 23 .

En el teatro el proceso fue semejante. El público comenzó a reclamar autenticidad. No le bastaba con sentirse humano a través del vivir español o francés, quería reconocerse en el escenario. Deseaba que el teatro fuera una tribuna donde se plantearan también las preguntas que llevaba consigo la toma de conciencia de lo mexicano. Carlos González Peña nos señala que surgió el imperativo de conocerse en la escena, de ver en ella reflejado " ¿cómo somos? ¿Qué pensamos? ¿Cuáles son nuestras costumbres, nuestros dolores, nuestras alegrías, nuestras esperanzas, nuestros desencantos? ¿Cuáles nuestra tradición y nuestra habla? ¿Cuáles los problemas que nos afectan, y, asimismo, cuál la visión del pasado cercano o remoto, así como la palpitación del presente?"' ${ }^{24}$

22 Ibid., p. 23.

${ }^{23}$ Pedro Henríquez Ureña, "La influencia de la Revolución en la vida intelectual de México", en Universidad y educación, México, 1969, p. 101. Véase a este propósito el ensayo "Apariencias arquitectónicas", de Jesús T. ACEVEDO, donde se defiende la arquitectura nacional, en Disertaciones de un arquitecto, México, 1920, pp. 21-65.

${ }^{24}$ Carlos GonZález Peña, "El teatro mexicano'" [1925], en El alma y la máscara, México, 1948, pp. 169-170. 
Elementos todos estos que habían permanecido marginados e incluso vedados de la representación teatral anterior a la Revolución.

Entre todas las expresiones del arte es, sin embargo, en la pintura donde con más ímpetu y éxito se ve el deseo de recuperar la circunstancia mexicana. Las mismas campañas revolucionarias permitieron a los mexicanos conocer su propio país, el colorido de sus gentes y lo majestuoso y variado de su paisaje. Pero lo que es todavía más importante, tomaron conciencia de que habían vivido en un período de colonialismo cultural, donde el pintor, quizás reflejando los gustos de su sociedad contemporánea, había pintado en México el paisaje europeo que añoraba, incluso en ocasiones sin haberlo visitado siquiera. Se tomó al mismo tiempo conciencia de que lo universal en el arte sólo se conseguiría a través de lo nacional, liberándose de la degradación que la imitación llevaba consigo. Alfredo Ramos Martínez nos ha dejado, en un ensayo publicado en 1921, un valioso documento de las dimensiones filosóficas de este sentir: "Todos sabemos que el arte es universal, que no tiene patria; pero en nuestro movimiento, en el caso que nos ocupa, es diferente: para llegar a hacer el arte verdadero, tenemos irremisiblemente que ir hacia lo nuestro, inspirándonos siempre, porque eso es lo que constituye nuestro medio ambiente. Los franceses han hecho el arte francés; Italia, el arte italiano; Holanda, el arte holandés, y así todos los grandes pueblos han hecho arte propio. Pues bien; esto no significa más que, esos grandes pueblos, han llenado su cometido: han sido sinceros intérpretes de su medio ambiente" 25 .

En este mismo año de 1921 es cuando comienza el resurgir de la pintura muralista y, por primera vez en su historia, México consigue una aportación universal en el campo de la pintura a través de Diego Rivera, José Clemente Orozco y David Alfaro Siqueiros. Una pintura que era tanto más universal en cuanto que era más mexicana. El mestizaje cultural que representaba la pintura de los muralistas no se detuvo en las manifestaciones artísticas, pues su radio de acción se fue ampliando hasta penetrar en el mismo sistema educativo; así la reforma de la enseñanza del dibujo iniciada por Adolfo Best Maugard ${ }^{26}$.

${ }^{25}$ Alfredo Ramos Martínez, "Nueva orientación del Arte Nacional”, El Maestro, 1 (1921), p. 95.

${ }^{26}$ La reforma consistía en enseñar a los niños las características del arte indígena que Pedro HenríQuez Ureña nos describe así: "El dibujo mexicano, que desde las altas creaciones del genio indígena en su civilización antigua ha seguido viviendo hasta nuestros días a través de las preciosas artes del pue- 


\section{ORTEGA y GASSET Y LA CIRCUNSTANCIA MEXICANA}

Una vez establecido el escenario de la circunstancia mexicana en las páginas precedentes, podemos ahora aproximarnos a la obra de Ortega e ir dando respuesta a las preguntas que nos formulamos al principio de este estudio. Aunque no poseemos datos concretos sobre la llegada de las primeras obras de Ortega y Gasset a México, se puede afirmar que ya a partir de 1916 se tenía noticias del filósofo español. Pero no fue hasta 1922 cuando su obra comenzó a ser discutida en los diversos círculos culturales. Parte de la difusión se debe también, sobre todo en su comienzo, a Alfonso Reyes, que en 1922 escribió un ensayo titulado "Apuntes sobre José Ortega y Gasset", incluido un año más tarde en su libro Los dos caminos. De todos modos, ni la difusión ni el éxito de su obra durante la década de los veinte puede explicarse por la labor de sus amigos o por la preocupación mexicana de Ortega. En realidad, aunque Ortega y Gasset hace referencia a Hispanoamérica en la nota editorial que introduce el primer número de la Revista de Occidente, su preocupación por el continente americano fue mínima y dirigida casi exclusivamente a los Estados Unidos y a la Argentina; México simplemente es ignorado ${ }^{27}$. Por otra parte, los mexicanos no fueron atraídos a Ortega del mismo modo que antes lo habían sido a Comte y Bergson. No se acercaron a su obra para imitarla; más bien al contrario, en Ortega encontraron su independencia. Vieron en algunos de sus postulados un espejo que reflejaba una respuesta epistemológica a sus problemas y a su circunstancia.

Las primeras obras que circularon en México fueron Meditaciones del Quijote y los tres primeros volúmenes de El espectador. Su

blo, está constituido por siete elementos (línea recta, línea quebrada, círculo, semicírculo, ondulosa, ese y espiral), que se combinan en series estáticas o dinámicas, petalillos y grecas, con la norma peculiar de que nunca deben cruzarse dos líneas, y pueden servir en combinación libre, para toda especie de representaciones y decoraciones"' (art. cit., p. 101).

${ }^{27}$ Esta actitud de Ortega no ha pasado inadvertida, sobre todo a aquellos pensadores que siguieron y proyectaron su obra. A este propósito nos dice LEOPOLDO ZEA: "José Ortega y Gasset, alguna vez, declaró a nuestro Alfonso Reyes el agrado que tendría de ser apodado Ortega el Americano, como se dijo en la antigüedad Escipión el Africano. Y he aquí que por lo que su obra representó para nuestra América, la hispánica, Ortega merece este apodo; pero a pesar suyo. Y digo a pesar suyo porque, independientemente de esa declaración, la simpatía de Ortega por América fue siempre limitada, llena de prevenciones. De la América Hispana sólo conoció la Argentina y se resistió siempre a entrar en contacto con el resto de ella", art. cit., p. 132. 
llegada coincide con los primeros años de la década de los veinte; es decir, coincide con el período en que, una vez finalizada la contienda armada, los mexicanos empiezan a analizar los resultados de la Revolución. Y coincide, sobre todo, con las primeras manifestaciones de un nuevo modo de vida y una nueva conciencia de lo mexicano, que ahora parece dominar en todas las ramas de las artes y que empieza a aplicarse al sistema educativo. Durante siglos se había vivido bajo la creencia en unos valores universales que se identificaban con los europeos. Ahora, sin que fuera motivado por un acuerdo intencional, se ve aparecer en el teatro, en la música, en la pintura, en la literatura, un nuevo arte, una nueva forma de expresar las emociones, un nuevo modo de interpretar lo universal. Además, todo parecía surgir espontáneamente del pueblo, casi sin la intervención de los intelectuales. No había duda, se había creado una nueva morada vital, se había llegado, en terminología de Usigli, al tercer acto, en el que "la revolución intelectual empieza" 28 . Ésta es la situación en que llega a México el pensamiento de Ortega y Gasset, un filósofo europeo, que adelanta el postulado de: "Yo soy yo y mi circunstancia, y si no la salvo a ella no me salvo yo"'29. También en Meditaciones del Quijote se afirmaba que "el hombre rinde el máximo de su capacidad cuando adquiere la plena conciencia de sus circunstancias. Por ellas comunica con el universo" "30. En verdad, no necesitaban los mexicanos largas explicaciones para comprender unos postulados teóricos que ellos habían llevado ya con tanto éxito a la práctica - piénsese en la pintura mural. En Ortega veían una confirmación de lo que ellos ya sentían. Además, si Ortega y Gasset se proponía describir el mundo desde el punto de vista de su situación particular, con el mismo derecho podían ellos, los mexicanos, hacer otro tanto; pues Ortega confirmaba su posición al afirmar que "la realidad no puede ser mirada sino desde el punto de vista que cada cual ocupa, fatalmente, en el universo. Aquélla y éste son correlativos, y como no se puede inventar la realidad, tampoco puede fingirse el punto de vista" 31 . El poder sugeridor de Ortega era inagotable. No sólo se encontraba en él una base

${ }^{28}$ Rodolfo Usigli, para quien la Revolución fue una "acción secular y vertiginosa que se anticipa al pensamiento que prepara", señala refiriéndose a la poca participación de los intelectuales en la Revolución: "La revolución intelectual empieza por el tercer acto" (México en el teatro, México, 1932, p. 119).

${ }^{29}$ José OrTega y Gasset, Meditaciones del Quijote. Ideas sobre la novela, Madrid, 1964, p. 30.

30 Ibid., p. 25.

31 José Ortega y Gasset, El espectador [1916], Madrid, 1966, t. 1, p. 23. 
para explicar el presente y trazar el camino a seguir en el futuro, sino que también apuntaba una explicación para el fracaso del pasado. En efecto, Ortega afirmaba que no "puede fingirse el punto de vista", y eso era precisamente lo sucedido a través de la historia mexicana; se había vivido y actuado según el punto de vista europeo, se había pretendido vivir en un pequeño París imaginario, de espaldas a la realidad mexicana, y se había fracasado en lo cultural, en lo social, en lo político.

Tal fue lo que los mexicanos hallaron en Ortega y Gasset: una confirmación de que la Revolución no había sido en vano, de que el nuevo modo de ver el mundo que de ella surgía era el auténtico. Pero Ortega iba todavía más allá. En el primer volumen de El espectador afirmaba también: "Donde está mi pupila no está otra [...] Somos insustituibles, somos necesarios [...] Dentro de la humanidad cada raza, dentro de cada raza cada individuo es un órgano de percepción distinto de todos los demás y como un tentáculo que llega a trozos de universo para los otros inasequibles'"32. O sea, interpretaban los mexicanos, no sólo es lo más real obrar como mexicanos, a través de nuestra circunstancia, sino que ésa es nuestra misión, ése es el lugar que hemos de llenar dentro de la historia universal. Ningún ejemplo mejor de este modo de operar que algunos aspectos de la obra de José Vasconcelos.

Por las mismas fechas en que llegó a México la obra de Ortega, hizo su aparición otro libro que venía a reforzar el ímpetu nacionalista del momento. Me refiero a la Decadencia de Occidente, de Oswald Spengler. El postulado central de esta obra, unido a las anteriores ideas de Ortega, hacía oportunas las tesis de Vasconcelos expuestas en La raza cósmica (1925) e Indología (1926). Vasconcelos parte de los supuestos de que "en la historia no hay retornos, porque toda ella es transformación y novedad", y que cada raza "plantea su misión, la cumple y se va". Ahora, apoyado en Spengler, afirma que "los días de los blancos puros, los vencedores de hoy, están contados"'33. El futuro, según Vasconcelos, estará en el mestizaje, en México, en Hispanoamérica, pues es allí de donde va a salir "la raza definitiva, la raza síntesis o raza integral, hecha con el genio y con la sangre de todos los pueblos y, por lo mismo, más capaz de verdadera fraternidad y de visión realmente universal" ${ }_{34}$. Ortega y Gasset había destruido para

32 Ibid., p. 24.

33 José Vasconcelos, La raza cósmica: Misión de la raza iberoamericana [1925], Madrid, 1966, p. 30.

34 Ibid., p. 36. 
siempre el monopolio sobre lo universal que los europeos se habían adjudicado. Pero este hecho, que en Europa podía pasar desapercibido, significaba para Hispanoamérica, y en nuestro caso concreto para los mexicanos, un romper con el pasado y un romper las cadenas que los habían mantenido subyugados. Era como si por primera vez adquirieran todos los derechos del ser humano. "Nosotros nos hemos educado - nos dice Vasconcelos- bajo la influencia humillante de una filosofía ideada por nuestros enemigos, si se quiere de una manera sincera; pero con el propósito de exaltar sus propios fines y anular los nuestros. De esta suerte nosotros mismos hemos llegado a creer en la inferioridad del mestizo, en la irredención del indio"35. El lema de Vasconcelos, "Por mi raza hablará el espíritu", pasaría luego a ser el de la universidad mexicana.

En 1923 publica Ortega y Gasset El tema de nuestro tiempo y de nuevo los mexicanos ven reflejado en él su circunstancia nacional. En este libro no sólo ampliaba Ortega aquello que estaba en germen en sus obras anteriores, sino que exponía también su teoría de las generaciones; y en ella encontraron los mexicanos una fórmula capaz de explicar las relaciones del "yo" con la "circunstancia", y que además permitía colocar la Revolución misma en perspectiva. Por una parte, Ortega fue usado como arma efectiva contra una minoría que abogaba por la introducción de un europeísmo idealista en la educación mexicana, y que ellos proponían en aras de una intención universalista que de nuevo identificaban con lo europeo. Contra "los europeístas", "los nacionalistas" afirmaban, con Ortega, que, hasta ahora, la filosofía había "sido siempre utópica. Por eso pretendía cada sistema valer para todos los hombres"' 36 . Además, "la divergencia entre los mundos de dos sujetos no determina la falsedad de uno de ellos. Al contrario, precisamente porque lo que cada cual ve, es una realidad y no una ficción, tiene que ser su aspecto distinto del que otro percibe. Esa divergencia no es contradicción, sino complemento" "37. Al mismo tiempo que así se daba primacía a la posición "nacionalista', se le abría también las puertas para su trascendencia universal al igualar lo mexicano con lo europeo, y al considerarlos ambos como partes necesarias en la búsqueda de una verdad más absoluta; actitud esta que Ortega de nuevo justifica-

35 Ibid., p. 55.

36 José Ortega y Gasset, El tema de nuestro tiempo [1923], Madrid, 1968, p. 87.

37 Ibid., p. 86. 
ba al afirmar que "cada individuo es un punto de vista esencial. Yuxtaponiendo las visiones parciales de todos se lograría tejer la verdad omnímoda y absoluta" 38 .

Pero la importancia de El tema de nuestro tiempo en México se debió, ante todo, al aporte que la teoría de las generaciones suponía en el intento de interpretación a que se estaban sometiendo los sucesos y resultados de la Revolución. Para los mexicanos era obvio que de 1910 a 1920 se había obrado un profundo cambio en la sensibilidad nacional. Y apenas comenzaban a analizar el fenómeno, cuando llegó la obra de Ortega en que se afirma que "las variaciones de la sensibilidad vital que son decisivas en la historia se presentan bajo la forma de generación" 39 . Pero además Ortega procede a definir lo que él entiende por generación, y lo hace en tales términos que el lector mexicano no puede evitar una visualización de su propia historia. En efecto, Ortega dice que "una generación no es un puñado de hombres egregios, ni simplemente una masa: es como un nuevo cuerpo social íntegro, con su minoría selecta y su muchedumbre [...] la generación, compromiso dinámico entre masa e individuo, es el concepto más importante de la historia, y, por decirlo así, el gozne sobre el que ésta ejecuta sus movimientos" 40 . La teoría de las generaciones venía, pues, a establecer ciertas prioridades en el proceso de la investigación. Se podía comenzar por fin a ordenar los datos que en confuso desorden surgían de los hechos de la Revolución misma. Si el concepto de la generación es el gozne sobre el que la historia ejecuta sus movimientos y si "cada generación representa una cierta altitud vital, desde la cual se siente la existencia de una manera determinada', el primer paso en el estudio de la Revolución sería el de establecer las características de la generación que la hacía posible. Ésta es la labor que se propone Manuel Gómez Morín en su libro, oportunamente titulado $1915^{41}$.

38 Ibid., pp. 89-90. En esta obra de Ortega y Gasset está la base de donde arranca el pensamiento mexicano actual y resulta imprescindible, por ejemplo, para comprender el alcance e innovación de la obra de Leopoldo Zea.

39 Ibid., p. 14.

40 Ibid., pp. 14-15.

41 Con anterioridad, en 1918, en la página editorial del número 12 de la revista San-ev-ank, había publicado Manuel de la Torre y Morali una nota bajo el título "El despertar de una generación". El término, sin embargo, no se define y la nota propone únicamente un curso de acción a seguir. La difusión del término y su uso en México proviene de la obra de Ortega, como señalaría después SAmUel Ramos: "Tengo entendido que en México no se habló de generaciones sino después de haberse leído el libro de Ortega y Gasset titulado El tema de nuestro tiempo, en donde se da una rigurosa significación 
Para Gómez Morín una generación es, en la historia de un pueblo, "un momento en esta lucha entre el realizar y el vivir, entre lo creado y el espíritu creador, entre lo que quiere ser y permanecer y lo que varía y en variar tiene su esencia, entre el espacio -la obra - y el tiempo - el obrar" ${ }_{42}$. Por ello cree que en una generación "la unidad de época, de manera o de acción, son a menudo sus aspectos externos", pues "la esencia de las generaciones debe buscarse en otra parte, en una íntima vinculación establecida entre varios hombres por la existencia en todos ellos, de un mismo impulso inefable, de una inquietud peculiar, de ciertas maneras profundas de entender y valorizar la vida y de plantear sus problemas" "43. Al analizar ahora Gómez Morín los sucesos hasta 1920, ve destacarse el año 1915 como el comienzo de una nueva conciencia sobre la realidad mexicana ${ }^{44}$. De este

de este concepto como base para una teoría de la historia. Esto ocurre más o menos en los años 1922 o 23 , y posteriormente se generaliza el empleo de aquel término hasta llegar muchas veces al abuso" (El perfil del hombre y la cultura en México [1934], en Obras completas, México, 1975, t. 1, p. 170). EmiLio URANGA señala igualmente: "Es común desde Ortega y Grasset hablar entre nosotros de generación y caracterizar a las generaciones como los sujetos realmente efectivos del devenir histórico"' (Análisis del ser del mexicano, México, 1952, p. 64). Véase también Problemas literarios, México, 1955, de José Luis MARTíNEZ, sobre todo en las secciones: "Vida de las promociones literarias" y "Constitución de las épocas literarias"; y Los 7 sabios de México, México, 1961, de Luis Calderón Vega. En verdad, para finales de la década de los veinte, el uso del término y concepto de generación se había difundido tanto, que se hará uso de él sin citar a Ortega; aunque en ocasiones se le siga de muy cerca, como sucede con el estudio de Enrique Martínez Ulloa, "Guadalajara", publicado en Bandera de Provincias, núms. 6 y 7 de 1929.

${ }^{42}$ Manuel Gómez Morín, op. cit., p. 28. Este aspecto que se halla implícito en El tema de nuestro tiempo, lo desarrollará después Ortega en su ensayo Ideas y creencias.

${ }^{43}$ Ibid., p. 26.

${ }^{44}$ Gómez Morín dice al respecto: "En el año de 1915, cuando más seguro parecía el fracaso revolucionario, cuando con mayor estrépito se manifestaban los más penosos y ocultos defectos mexicanos y los hombres de la Revolución vacilaban y perdían la fe, cuando la lucha parecía estar inspirada nomás por bajos apetitos personales, empezó a señalarse una nueva orientación. El problema agrario, tan hondo y tan propio, surgió entonces con un programa mínimo definido ya, para ser el tema central de la Revolución. El problema obrero fue formalmente inscrito, también, en la bandera revolucionaria. Nació el propósito de reivindicar todo lo que pudiera pertenecernos: el petróleo y la canción, la nacionalidad y las ruinas [...] Del caos de aquel año nació la Revolución. Del caos de aquel año nació un nuevo México, una idea nueva de México y un nuevo valor de la inteligencia de la vida. Quienes no vivieron ese año de México, apenas podrán comprender algunas cosas" (op. cit., pp. 9-11). 
modo, mediante el concepto de generación se comienza por primera vez, de manera sistemática, el estudio de la Revolución, dividiendo el proceso en dos grandes apartados: el de la revolución misma en su dimensión irracional, de confusión, de la fuerza ciega de la masa popular en revuelta, y el de los individuos que por su actuación se destacaron. Éstos son, por decirlo así, los personajes de un drama que toman conciencia de su individualidad al mismo tiempo que se reconocen ineludiblemente relacionados y limitados por el coro - la acción de la masa.

En este mismo año de 1923 y coincidiendo con la publicación de El tema de nuestro tiempo, José Ortega y Gasset inició un nuevo proyecto, la Revista de Occidente, que durante más de una década sería el órgano más influyente en la vida intelectual hispanoamericana. Pero la llegada de la Revista de Occidente supone también una nueva etapa en la presencia de Ortega en México. Antes de internarnos en este nuevo aspecto, debemos todavía considerar la repercusión de un escrito de Ortega, publicado en 1925 en el cuarto tomo de El espectador. Me refiero a su ensayo "Carta a un joven argentino que estudia filosofía". La "Carta" va dirigida a un argentino y se habla de Sudamérica, pero los mexicanos no pudieron menos que verse en ella reflejados ${ }^{45}$. En su ensayo Ortega sentencia que "es imposible hacer nada importante en el mundo si no se reúne esta pareja de calidades: fuerza y disciplina. La nueva generación goza de una espléndida dosis de fuerza vital, condición primera de toda empresa histórica; por eso espero en ella. Pero a la vez sospecho que carece por completo de disciplina interna - sin la cual la fuerza se desagrega y volatiliza-; por eso desconfío de ella. No basta curiosidad para ir hacia las cosas; hace falta rigor mental para hacerse dueño de ellas" 46 . Los mexicanos reconocieron el defecto y aceptaron el desafío. Un año más tarde Gómez Morín hará eco de la crítica orteguiana: “ Necesitamos, ante todo, método y crítica. Crítica de nosotros mismos que nos ponga incesantemente en guardia contra las acechanzas de este medio tan propicio a la improvisación o contra los excesos de nuestro entusiasmo" 47 . Ortega y Gasset en su ensayo afirmaba además algo que llegaba al nervio más profundo del momento mexicano: "Son ustedes más sensibles que precisos

${ }^{45}$ Martín Luis GuzMÁn combate ya en 1915 lo que él llama "este arsenal de superficialidad y pedantería", y acusa que uno de los males de México ha sido la improvisación continua, La querella de México, p. 10.

46 José Ortega y Gasset, El espectador, Madrid, 1966, t. 4, p. 157.

47 Manuel Gómez Morín, op. cit., p. 50. 
y, mientras esto no varíe, dependerán ustedes íntegramente de Europa en el orden intelectual" 48 . El nacionalismo mexicano se sintió aludido y se vio culpable y reaccionó. Comenzó así un período de autocrítica y de precisión que simboliza ante todo la obra de Samuel Ramos. De tal modo triunfó el intelectual mexicano, que ya en 1942 podría decir Reyes: "Esta súbita aparición de una responsabilidad inesperada es lo que mejor contribuye a madurar a los pueblos y a los hombres" 49 .

\section{El ORTEGA MEXICANO}

Con la publicación en 1923 de la Revista de Occidente, el desarrollo del pensamiento mexicano entra en una nueva etapa. La misma circunstancia mexicana y la influencia de los libros de Ortega crearon en México un ambiente propicio para el desarrollo del pensamiento. Se había formado una nueva conciencia sobre el propio valer y se había incitado la curiosidad por el conocimiento. "Por medio de la Revista de Occidente - nos dice Samuel Ramos - los estudiosos de México se pusieron en contacto con el pensamiento alemán contemporáneo y se despertó el interés por leer las obras de sus grandes filósofos" ${ }^{20}$. Se comenzaron a leer con avidez las traducciones españolas de los pensadores alemanes y los mismos jóvenes mexicanos, imitando la trayectoria de Ortega, fueron a estudiar a Alemania. Así lo hicieron, entre otros, Samuel Ramos ${ }^{51}$, Eduardo García Máynez y Francisco Larroyo. La difusión y la influencia de la Revista fue inmediata; Torres Bodet dice a este propósito que ya a finales de 1923 "Villaurrutia era un lector fervoroso de la Revista de Occidente. No tardamos nosotros en seguirle en aquella afición" 52 . Pero si la Revista de Occidente representaba una culminación en la labor de líder intelectual

${ }^{48}$ José Ortega y Gasset, El espectador, t. 4, p. 157. José Romano MuÑZ hace referencia a esta afirmación de Ortega, a quien cita textualmente en su estudio " $\mathrm{Ni}$ irracionalismo ni racionalismo, sino filosofía crítica", Ulises, 4 (1927), 4-10.

49 Alfonso Reyes, Obras completas, México, 1969, t. 11, p. 255.

50 Samuel Ramos, Historia de la filosofía en México, en Obras completas, México, 1976, t. 2, p. 227.

51 Samuel Ramos, en realidad, estudió en Francia el pensamiento alemán.

52 Jaime Torres Bodet, Obras completas, México, 1961, p. 293. Se refiere aquí al grupo de intelectuales que trabajaba con él en el Departamento de Salubridad: Enrique González Rojo, José Gorostiza y Bernardo Ortiz de Montellano. 
que se había asignado a Ortega y Gasset, suponía también una apertura a otras ideas que darían base para combatir los propios postulados orteguianos. En efecto, a partir de 1923 el pensamiento mexicano iba adquiriendo ya su mayoría de edad, con conciencia de su valor y de su singularidad.

He encabezado esta sección con el título de "El Ortega mexicano", y lo hice así porque nos conviene ahora destacar la existencia de tres "Ortegas" en el desarrollo del pensamiento mexicano. Un Ortega, por todos aceptado, representa, en palabras de Francisco Romero, al “jefe espiritual”. O sea, en él se reconoce al líder intelectual que más influyó en el pensamiento hispanoamericano en la década de los años veinte, y que queda simbolizado por su labor en torno a la Revista de Occidente. El segundo Ortega corresponde al autor de Meditaciones del Quijote, El espectador, El tema de nuestro tiempo y luego Ideas y creencias, Historia como sistema y otros ensayos posteriores. Éste es el Ortega que más ha influido en el desarrollo de una filosofía de lo mexicano; su pensamiento no sólo sigue actual hoy día en México, sino que, mediante Samuel Ramos primero y Edmundo O'Gorman y Leopoldo Zea después, está siendo llevado a nuevos niveles de creación filosófica. Pero a pesar de su presencia dominadora en el momento actual mexicano, este segundo Ortega ha sido y es combatido por otros grupos de pensadores mexicanos, entre ellos por los neo-escolásticos y los neo-kantianos. El tercer Ortega, por lo general ignorado cuando no combatido en México, es el autor de La deshumanización del arte, Ideas sobre la novela, La rebelión de las masas y otros ensayos semejantes.

El Ortega hasta aquí estudiado era para los mexicanos símbolo del auténtico filósofo en defensa de su individualidad y que reclamaba su independencia de cualquier filosofía que se creyera única portadora de la verdad. En realidad, de Ortega aceptaron los mexicanos sólo su grito de autodeterminación: "Yo soy yo y mi circunstancia, y si no la salvo a ella no me salvo yo". En este postulado estaba, por supuesto, implícito el posible rechazo del mismo Ortega. Por ello, mientras continuó desarrollando esta idea básica, sus obras eran aceptadas como proyección del pensamiento propio, pues mediante ellas los mexicanos también se emancipaban, se afirmaban más en su propia creación filosófica. No imitaban por lo tanto a Ortega, más bien lo seguían en su espíritu independiente. Interpretada de este modo su influencia, no extraña que la publicación de La deshumanización del arte, Ideas sobre la novela y La rebelión de las masas fuera prácticamente ignorada en el medio cultural mexicano. Estas obras, como después veremos, 
mostraban a un pensador europeo que nuevamente pretendía dar carácter universal a una posible realidad europea.

En la nota editorial al primer número de la Revista de Occidente Ortega había afirmado, con el aplauso general de sus lectores hispanoamericanos: "Procurará esta revista ir presentando a sus lectores el panorama esencial de la vida europea y americana". Dos años más tarde, en 1925, publica Ortega La deshumanización del arte. En todo el ensayo no se hace una sola referencia a Hispanoamérica. Además, en un libro cuyas reflexiones se basaban en gran medida en la pintura, se ignoraba, por desconocimiento o por menosprecio, el arte muralista que ya desde 1921 había triunfado en México. Hablar del arte moderno y omitir el movimiento muralista mexicano significaba ya de por sí dejar truncada la obra y dudosas sus conclusiones. Pero además sucedía que precisamente las obras de Rivera, Orozco y Siqueiros representaban una rotunda contradicción a la tesis orteguiana. Así fue visto este libro en México, donde adquirió poca difusión y fue denunciado por la crítica, cuya posición queda elocuentemente representada por Jaime Torres Bodet: "La deshumanización del arte es un libro europeo, con datos europeos, escrito para europeos" " 53 , y añade más adelante: "su calidad de hombre de Europa lo justifica. Pero ¿y América? ¿Por qué olvidar las posibilidades del arte nuevo, las reservas de ingenuidad que esconde nuestra América? ¿Y por qué es Ortega y Gasset quien lo olvida, él que se enorgullecía, al volver a España de su viaje por las tierras de Argentina, de que en «las páginas de El espectador no se pusiera ya el sol»?" 54 Además, creía Torres Bodet que por su fama, tan efectiva en aquellos años, "ponía en peligro a no pocos jóvenes de Hispanoamérica, invitándoles a menospreciar lo más natural y espontáneo de su talento, sus aptitudes más sanas, su juventud" 55 .

La recepción que tuvo el ensayo Ideas sobre la novela fue semejante. Su llegada a México coincide además con el éxito de la publicación de Los de abajo, de Azuela, como folletín en las páginas de El Universal Ilustrado. Por otra parte, la afirmación de Ortega

${ }^{53}$ Jaime Torres Bodet, Contemporáneos: Notas de crítica, México, 1928, p. 125.

54 Ibid., p. 126.

${ }^{55}$ Jaime Torres Bodet, Obras completas, p. 315. Tan significativas como estas palabras fueron las reacciones a que dio lugar su estudio. Así nos señala años más tarde el mismo Torres Bodet: "Mi artículo suscitó varias adhesiones, sobre todo en América. Y algunas críticas, sobre todo en España" (p. 317). Jorge Cuesta considera La deshumanización del arte "un ensayo lleno de errores", Ulises, 4 (1927), p. 31. 
de que "es prácticamente imposible hallar nuevos temas"”56 resultaba para los mexicanos más que absurda, incomprensible. En realidad, la circunstancia mexicana apenas había sido explorada y, a juzgar por las obras que iban haciendo su aparición, el género estaba preñado de posibilidades para la creación de una literatura mexicana de alcance universal. Por otra parte el mexicano se daba cuenta, quizás precisamente por la riqueza que su circunstancia le ofrecía, que el tema era lo secundario en la novela. Así lo expresó Torres Bodet: "La decadencia de la novela es, para Ortega y Gasset, cuestión de cantidad de temas. No hemos de hacer causa común con él, en este camino de regreso al naturalismo. Ninguna obra de arte vive del tema que expresa" ${ }^{57}$.

Pero la obra que más destaca por el casi absoluto silencio que de ella se hace en la crítica y los escritos mexicanos es La rebelión de las masas $^{58}$. Las razones que causan el menosprecio de los mexicanos por este libro parecen obvias. Ortega de nuevo estudiaba un fenómeno europeo, y su controvertible punto de vista reflejaba al sentir de una minoría aristocrática - y este término quizás debiera entenderse más con el significado tradicional que con el nuevo sentido que le daba Ortega. Por otra parte, las ideas expresadas en el libro estaban en pugna con la realidad mexicana y con los principios democráticos que motivaron a la Revolución. Ésta, además, había sido obra casi exclusiva del pueblo, de la masa que ahora condenaba Ortega; a ella debía México su Constitución y su conciencia nacional.

56 José Ortega y Gasset, Meditaciones del Quijote. Ideas sobre la novela, Madrid, 1964, p. 162. Ortega todavía fue más allá al afirmar categóricamente: "En suma, creo que el género novela, si no está irremediablemente agotado, se halla, de cierto, en su período último" (p. 164).

${ }^{57}$ Jaime Torres Bodet, Contemporáneos: Notas de crítica, p. 9. Por lo general los críticos mexicanos ignoraron este ensayo de Ortega; y las referencias que a él se hacen al hablar de otras obras coinciden en negarle valor. Así, por ejemplo, la reseña que Rubén SALAZAR MALLÉN hace de Sin novedad en cl fren$t e$, de Erich M. Remarque, comienza con una referencia a Ortega y Gasset para indicar que su interpretación de la novela resulta incorrecta (Contemporáneos, 5, 1929, 75-78.)

58 Véase Jorge Cuesta, "La rebelión de las masas", Contemporáneos, 9 (1931), 152-165. Para un europeo la crítica de Cuesta parecerá en verdad extraña. Quizás en ello resida su valor; pues representa la reacción que desde una perspectiva distinta, la circunstancia mexicana, se tiene ante un mismo fenómeno, el estudiado por Ortega y Gasset. 
Presencia de Ortega en México

Partimos al principio del análisis de la circunstancia mexicana para después poder comprender las repercusiones de la obra de Ortega y Gasset. Ésta, a su vez, aparece tan unida a la toma de conciencia de la realidad mexicana que sólo en su relación adquiere significado. El Ortega que se acepta es aquel que proporciona una respuesta epistemológica al ansia de autenticidad que dominaba en todas las facetas de la vida mexicana, según ésta surge de la década revolucionaria. A partir de 1923, con la llegada de la Revista de Occidente, la influencia de Ortega es de otro sentido. La Revista introduce en México el pensamiento alemán, e incita y anima a los jóvenes mexicanos a explorar las nuevas tendencias europeas y a seguir estudios especialmente en las universidades alemanas. Desde esa fecha también la influencia de Ortega comenzará a ser poco a poco indirecta, y se efectuará a través de aquellos pensadores que dirigieron la vida intelectual mexicana en las siguientes décadas: Samuel Ramos, José Gaos y Leopoldo Zea.

Ramos se destacó ya en 1928 con la publicación de Hipótesis y se consagró en 1934 con su libro El perfil del hombre y la cultura en México. Desde entonces fue el guía intelectual de la juventud mexicana, sobre todo a través de sus enseñanzas en la Facultad de Filosofía y Letras. En 1941 creó la primera cátedra de Historia de la Filosofía en México y en 1943 publicó como libro de texto Historia de la filosofía en México, primera presentación sistemática del desarrollo del pensamiento mexicano, y base de todos los estudios posteriores al respecto. La influencia de Ortega en Ramos es indudable y él mismo lo ha señalado repetidas veces: "En esta frase de Ortega: "Yo soy yo y mi circunstancia, y si no la salvo a ella no me salvo yo" veía el que esto escribe, una norma que aplicar a México, cuya realidad y cuyos problemas eran completamente desconocidos para la filosofía ... Con estos propósitos el autor publicó en 1934 un libro titulado El perfil del hombre y la cultura en México" 59 . Esta afirmación de Ramos, luego repetida por la crítica para justificar el clasificarlo como discípulo de Ortega, debe ser considerada en un contexto especial. Ramos no imitó a Ortega y Gasset. Encontró en sus postulados, eso sí, su propio pensamiento madurado. Bástenos para apoyar esta afirmación lo ya expuesto aquí sobre la circunstancia mexicana de principios

${ }^{59}$ Samuel Ramos, Historia de la filosofía en México, en Obras completas, t. 2 , pp. 222-223. 
de los años veinte, y la siguiente cita tomada del primer escrito de Ramos, "La teoría biológica del conocimiento", de 1919, antes de su encuentro con Ortega. Dice Ramos: "La historia de la inteligencia, como la historia de todo lo que vive, no puede estudiarse aisladamente del medio, ya que todas las actividades cósmicas dependen las unas de las otras; y sobre todo tratándose de una actividad de relación como es la inteligencia. Ésta se ha formado en contacto con el ambiente' '60. Luego vendrá, a partir de 1922, la influencia de Ortega y del pensamiento alemán, pero en ellos Ramos encuentra sólo confirmado y proyectado su propio pensamiento, que después, en Hacia un nuevo humanismo, de 1940 , hará suyo y proyectará a nuevos niveles de creación filosófica. De este modo, con un desarrollo paralelo al de Ortega, e incluso superándolo en su concreción mexicana, establece Ramos en Hacia un nuevo humanismo las bases de la filosofía de lo mexicano: "Cada individuo tiene un mundo concreto como parte de su existencia, que es la única ventana de que dispone para asomarse al mundo en general. Quiero decir que lo que cada sujeto conoce mejor que cualquier otro es el paisaje natural en que vive, la sociedad, el país a que pertenece. Estas cosas las conoce desde adentro, por decirlo así, porque son la mitad de sí mismo, está vitalmente fundido con ellas. Estos objetos concretos tienen que ser por fuerza las instancias particulares que den vida y color a sus conceptos genéricos del universo, la humanidad o la sociedad. Pese al valor objetivo de las ideas que es independiente del espacio o del tiempo, al pensarlas tenemos que referirlas queramos o no al círculo de nuestras experiencias inmediatas. Esto es, sin duda, una limitación de nuestro conocimiento, pero también, por otro lado, una ventaja, la de descubrir en el mundo algo que los demás no podrían nunca ver"'61.

El magisterio de Samuel Ramos quedó reforzado a partir de 1938 con la llegada de los exiliados españoles, sobre todo mediante la obra y magisterio de José Gaos. Gaos, que fiel a su pensamiento filosófico rechaza el término de exiliado para adjudicarse el de “transterrado", puede y debe ser estudiado dentro de la historia del pensamiento mexicano, no sólo porque escribió su obra más importante en México, sino porque toda ella responde también a la circunstancia mexicana. En su pensamiento, menos creativo que el de Samuel Ramos, sigue explícitamente la obra de Ortega: "Siempre me he reconocido yo mismo, por discípulo de Or-

60 Samuel Ramos, Obras completas, t. 1, p. 217.

61 Ibid., t. 2, p. 20. 
tega y Gasset. Hasta me he tenido, y no sólo íntimamente, sino también más o menos públicamente, por su díscipulo más fiel y predilecto"'62. Incluso llega a decir en polémica con Francisco Larroyo: "Durante años he vivido en convivencia frecuentemente diaria con él [Ortega y Gasset]. He sido el oyente de palabras o el interlocutor de conversaciones en que se precisaban sus propias ideas en gestación, he leído manuscritos inéditos. Así, ya no sé si tal idea que pienso, si tal razonamiento que hago, si tal ejemplo o expresión de que me sirvo, lo he recibido de él, se me ocurrió al oírle o leerle a él, o se me ocurrió aparte y después de la convivencia con él. Alguna vez me ha sucedido comprobar que tal idea o expresión que consideraba como mía me la había apropiado de él, asimilándola hasta el punto de olvidar su origen"'63. Estas afirmaciones de Gaos son tanto más significativas cuando se considera que Justino Fernández, Edmundo O'Gorman y Leopoldo Zea fueron discípulos suyos. En realidad, la formación de los pensadores más destacados del México actual se debe a la labor conjunta de Samuel Ramos y José Gaos, y mediante ellos al pensamiento que incitó Ortega y Gasset.

Pero Gaos no sólo difundió el pensamiento de Ortega, y basado en sus postulados estudió y enjuició el pensamiento mexicano, sino que fue también un decidido defensor de la dirección que el historicismo orteguiano estaba adquiriendo en México. Su carácter y enérgica posición le hicieron participar en diversas polémicas, cuyo resultado fue ante todo el de difundir de nuevo las ideas orteguianas ${ }^{64}$.

62 José Gaos Confesiones profesionales, México, 1958, pp. 60-61.

63 José Gaos y Francisco Larroyo, Dos ideas de la filosofía. Pro y contra la filosofía de la filosofía, México, 1940, p. 192.

64 En 1943 publicó José SÁNCHez VILLASEÑor Pensamiento y trayectoria de José. Ortega y Gasset, México, 1943, en el cual, desde una posición que parte de la escolástica, critica de un modo severo y sistemático la obra de Ortega. Al año siguiente vuelve SÁNCHEz VILLASEÑor a atacar la obra de Ortega, esta vez desde un ángulo más emotivo, en un breve ensayo de 39 páginas, ¿ Es idealista Ortega y Gasset?, México, 1944; en 1945 da a la prensa otro libro en el que critica a José Gaos; y la obra aparece bajo dos títulos: uno en la sobrecubierta, Gaos en Mascarones, y el otro más formal, en el libro mismo, La crisis del historicismo y otros ensayos, México, 1945; al final del libro incluye el ensayo $i E s$ idealista Ortega y Gasset? José Gaos no dio respuesta directa a estos libros, pero en su ensayo "Cinco años de filosofía en México", publicado en 1945 en la revista Filosofía y Letras, sí que hace referencia al último libro de Sánchez Villaseñor; este ensayo lo incluyó luego en Filosofía mexicana de nuestros días, México, 1954. En 1949 GuIllermo HÉCTOR Rodríguez, neokantiano, publicó un ensayo, La filosofía en México, México, 1949, 34 pp., donde, además de la obra 
Aunque la influencia de Gaos continuó hasta bien entrada la década de los sesenta, para el estudio del pensamiento mexicano debemos considerar el año de 1948 como el comienzo de una nueva etapa. En este año el Grupo Filosófico Hiperión presentó una serie de conferencias en la Facultad de Filosofía y Letras, bajo el título "Problemas de la filosofía contemporánea", y un año más tarde otra serie, “¿Qué es el mexicano?" En 1952 comenzaron a publicar la colección "México y lo Mexicano", que inicia un consciente y mantenido esfuerzo por recuperar y explicar la circunstancia mexicana ${ }^{65}$. A partir de entonces se destacan dos pensadores, Edmundo O'Gorman y Leopoldo Zea; pero en ambos ya no es tan importante la posible influencia de Ortega o de sus discípulos, como los elementos propios con los que superan lo anterior para llegar a crear una filosofía que con todo derecho puede llamarse mexicana.

\section{José Luis Gómez-Martínez}

The University of Georgia

de Ortega, critica a los pensadores mexicanos influidos por él. Pero la reacción más fuerte contra la obra de Ortega tuvo lugar, sin embargo, en 1950. En este año Agustín Basave publicó, con un prólogo de Vasconcelos, Miguel de Unamuno y José Ortega y Gasset: Un bosquejo valorativo, México, 1950. También en ese año publica Eduardo Nicol, Historicismo y existencialismo, México, 1950; GAOS comenta el libro de Nicol en "De paso por el historicismo y existencialismo", CuA 1951, núm. 2, 122-135; y de modo más extenso en "De paso por el historicismo y existencialismo. Parerga y paralipómena', $F y L, 1951$, núms., 43/44, 81-148; ambos estudios se incluyeron después en su libro Sobre Ortega y Gasset y otros ensayos de historia de las ideas, México, 1957. Por su parte, EDUARDO Nicol contestó al primer estudio de Gaos en "Otra idea de la filosofia. Resnuesta a José Gaos", CuA, 1951, núm. 3, 129-139; y al segundo ensayo de Gaos en "Diálogo de filosofía entre el autor y el crítico", $F y L, 1951$, núms. 43/44, 149-175.

${ }^{65}$ Los miembros originarios del grupo Hiperión fueron: Leopoldo Zea, jefe del grupo y director de la colección "México y lo Mexicano", Ricardo Guerra, Joaquín MacGregor, Octavio Paz, Jorge Portilla, Salvador Reyes Nevares, Emilio Uranga, Fausto Vega y Luis Villoro. En la colección “México y lo Mexicano" publicaron también Alfonso Reyes y José Gaos. Véase al particular el extenso estudio de Roberto Cantú, "De Samuel Ramos a Emilio Uranga", Campo Libre, 2 (1981), 239-272. 